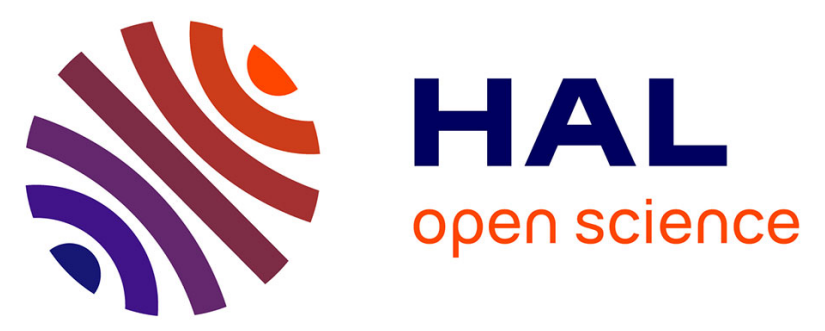

\title{
Quantum Dash Actively Mode-locked Fabry-Perot Laser Module demonstrated as part of a Wavelength Tunable RZ Transmitter
}

Gwenaëlle Girault, Mathilde Gay, Sebastien Lobo, Laurent Bramerie, Michel Joindot, Jean-Claude Simon, Alexandre Shen, F. Blache, H. Gariah, F. Mallecot, et al.

\section{To cite this version:}

Gwenaëlle Girault, Mathilde Gay, Sebastien Lobo, Laurent Bramerie, Michel Joindot, et al.. Quantum Dash Actively Mode-locked Fabry-Perot Laser Module demonstrated as part of a Wavelength Tunable RZ Transmitter. Electronics Letters, 2008, Vol.44 (Issue 14), pp.873-874. 10.1049/el:20080806 . hal00352745

\section{HAL Id: hal-00352745 \\ https://hal.science/hal-00352745}

Submitted on 13 Jan 2009

HAL is a multi-disciplinary open access archive for the deposit and dissemination of scientific research documents, whether they are published or not. The documents may come from teaching and research institutions in France or abroad, or from public or private research centers.
L'archive ouverte pluridisciplinaire HAL, est destinée au dépôt et à la diffusion de documents scientifiques de niveau recherche, publiés ou non, émanant des établissements d'enseignement et de recherche français ou étrangers, des laboratoires publics ou privés. 


\title{
Quantum Dash Actively Mode-locked Fabry-Perot Laser Module demonstrated as part of a Wavelength Tunable RZ Transmitter
}

\author{
G. Girault, M. Gay, S. Lobo, L. Bramerie, M. Joindot, J.C. Simon \\ A. Shen, F. Blache, H. Gariah, F. Mallécot, O. Le Gouezigou, F. Poingt, L. \\ Le Gouezigou, F. Pommereau, B. Rousseau, F. Lelarge, G-H. Duan
}

A quantum dash Fabry-Perot actively mode locked laser module is tested as part of a $42.7 \mathrm{Gbit} / \mathrm{s}$ transmitter with more than $10 \mathrm{~nm}$ wavelength tunability. Its low chirp level is also assessed through chromatic dispersion tolerance measurements.

Introduction: Mode-locked laser diodes (MLLDs) have a great potential for many applications in optical communications such as optical time-division multiplexing [1] or optical clock recovery [2, 3]. Furthermore, multi-wavelength lasers have become attractive as they enable to obtain a large number of wavelength-division-multiplexing (WDM) channels from a single source $[4,5]$. Future WDM light sources must meet a number of criteria such as simple and stable operation, cost effectiveness and low energy consumption. Quantum Dash (QD) Fabry-Perot (FP) MLLDs are promising candidates as they meet all of the above criteria. In addition these components have a small footprint, hold possibilities for monolithic integration and have recently shown the possibility to generate short pulses over a wide spectral bandwidth through passive filtering [6]. This last reference deals with spectral and temporal characterizations performed thanks to the linear spectrogram method [7]. 
In this Letter, a 42.7 Gbit/s RZ transmitter using the QD FP MLLD module is assessed thanks to Bit Error Rate (BER) measurements, and its chirp is evaluated through chromatic dispersion tolerance investigations.

Source description and characterisation: The chip and the module were fabricated at III-V lab [6]. The QD-based hetero-structures were grown by GSMBE on a S-doped (100) InP wafer. The active core consists in 6 InAs QDs layers and a GalnAsP injector quantum well which is separated by a thin InP barrier designed for phonon-assisted tunnel injection ( $\mathrm{TI}$ ) lasers emitting at $1.55 \mu \mathrm{m}$. The $\mathrm{TI}$ layers are enclosed within barriers and two separate confinement hetero-structure $(\mathrm{SCH})$ layers. Along with the FP chip, a temperature probe, a Peltier cooler and a micro-wave V-type connector have been integrated into a butterfly module.

The optical spectrum from the passively MLLD module is presented on Fig 1. As shown in [6], the spectrum is quite flat and centred at $1555 \mathrm{~nm}$, with a $3 \mathrm{~dB}$ width of $19 \mathrm{~nm}$. This wide spectrum allows to achieve a tunable source using an external optical filter (represented by a dashed line on the left hand side of Fig. 1)

Thus when using the module in a $40 \mathrm{GHz}$ actively mode-locking configuration with a Gaussian optical filter with a $3 \mathrm{~dB}$ bandwidth of $0.6 \mathrm{~nm}$, we obtained an optical clock showing a full width at half maximum (FWHM) of $6.3 \mathrm{ps}$ and a timing jitter of 500 fs. The module was then driven by a $20 \mathrm{dBm}, 42.7 \mathrm{GHz}$ electrical clock and a bias current of $300 \mathrm{~mA}$ was used. Temporal characterizations, shown on the right hand side of Fig 1, were obtained with 
an optical sampling oscilloscope (with 1 ps time resolution, and $150 \mathrm{fs}$ jitter resolution).

BER assessment: The experimental setup is presented on Fig 2. Either a reference source or the QD FP MLLD module was used in the transmitter in order to make a comparison. The reference source, delivering a classical RZ $33 \%$ signal, consisted in a tunable continuous laser followed by an $\mathrm{x}$-cut $\mathrm{LiNbO}_{3}$ modulator, driven by a $21.3 \mathrm{GHz}$ sinusoidal clock. The QD FP MLLD module was driven by a $42.7 \mathrm{GHz}$ electrical clock and a bias current (Ibias) of $300 \mathrm{~mA}$. Both optical clocks (reference and QD FP MLLD) were coded via an x-cut $\mathrm{LiNbO}_{3}$ modulator driven by a $2^{31}-1$ PRBS at $42.6 \mathrm{Gbit} / \mathrm{s}$, generated by multiplexing electrically four trains at $10.66 \mathrm{Gbit} / \mathrm{s}$. In the case of the QD FP MLLD, a tunable optical filter (OF\#1) shaped the signal, according to the principle displayed on the left hand side of Fig 1. Finally the signal was analyzed after detection in an optically preamplified receiver followed by an electrical demultiplexer (ETDM).

Firstly we assess the tunability of the QD FP MLLD module through receiver sensitivity measurements. For such a purpose we measured the required receiver input power for a BER of $10^{-9}$ (called sensitivity) at different wavelengths (from $1550 \mathrm{~nm}$ to $1560 \mathrm{~nm}$ ) by tuning the optical filter (OF\#1). We compared three kinds of transmitters: the reference source and the QD FP MLLD with two different Gaussian optical filters (OF\#1) with $3 \mathrm{~dB}$ bandwidths of respectively 0.25 and $0.6 \mathrm{~nm}$.

Results are presented on Fig. 3 where the sensitivity is depicted versus the wavelength. In the right hand side of the figure, the corresponding eye 
diagrams are displayed. The pulse FWHM of the reference source is 8.25 ps; those of the QD FP MMDL with respectively the $0.6 \mathrm{~nm}$ and $0.25 \mathrm{~nm}$ wide filters are $6.3 \mathrm{ps}$ and $14.4 \mathrm{ps}$.

In the case of the reference source, the sensitivity is equal to $-31 \mathrm{dBm}$ over the entire C-band. In the case of the $0.6 \mathrm{~nm}$ filter, the sensitivity was measured at $-32 \pm 0.25 \mathrm{dBm}$ over the studied spectral bandwidth (from 1550 $\mathrm{nm}$ to $1560 \mathrm{~nm}$ ), showing a quite stable transmitter. The sensitivity improvement compared to the reference result is due to the shorter pulse width, a well known effect [9]. In the case of the $0.25 \mathrm{~nm}$ filter, the mean sensitivity is equal to $-31.5 \pm 1 \mathrm{dBm}$. The larger variation of the sensitivity might be linked to the higher wavelength selectivity of the filter.

This BER assessment demonstrates for the first time the high quality of the QD FP MLLD module over $10 \mathrm{~nm}$ when used as part of a $40 \mathrm{Gbit} / \mathrm{s}$ transmitter.

Secondly, we evaluated the chirp of the QD FP MLLD module by investigating the influence of chromatic dispersion (CD) on the receiver sensitivity. Indeed in the case of an unchirped signal, the CD leads to a degradation of the receiver sensitivity (pulse broadening) and thus the penalty versus $C D$ curve is symmetrical with respect to the normal or anomalous dispersion. On the contrary for a chirped signal, the CD can lead to pulse narrowing and thus improving the penalty and shift the minimum penalty from the zero dispersion point [8].

For this experiment we included a tunable CD module (centred at $1550 \mathrm{~nm}$ and with a $1 \mathrm{ps} / \mathrm{nm}$ step) in front of the receiver. Then we measured the penalty (for a BER of $10^{-9}$ ) induced by the CD at $1550 \mathrm{~nm}$ for the three same 
configurations as previously. The penalty is defined here as the receiver sensitivity variation when chromatic dispersion is added.

Results are plotted on Fig.4. As the chirp results into a shift of the minimum penalty from the zero CD point, we looked at this parameter. As the minimum penalty point is not easy to identify accurately, we introduced $\langle$ CD $>$ defined as the average value of the two dispersion values associated with a given penalty, here $3 \mathrm{~dB}$. It equals $+6.5 \mathrm{ps} / \mathrm{nm}$ in the reference case, showing a really low chirped transmitter. In the case of the $0.25 \mathrm{~nm}$ filter, $<C D>$, equal to $+5 \mathrm{ps} / \mathrm{nm}$, and the CD tolerance are equivalent to the case of the reference signal. Now in the case of the $0.6 \mathrm{~nm}$ filter, the CD tolerance is weaker as the pulses are shorter, however $\angle C D>$ is still close to zero $(-5 \mathrm{ps} / \mathrm{nm})$. To sum up, in both configurations of the QD FP MLLD module, offsets of the penalty curve are comparable to that of the reference and close to zero indicating a low chirped source module.

Conclusion: In this paper we demonstrated the high quality of a QD FP actively MLLD module used in a 42.7 Gbit/s transmitter. The pulse width of the transmitter was adjusted using optical filtering. The receiver sensitivity, typically $-32 \mathrm{dBm}$ for $6.3 \mathrm{ps}$ width pulses and $-31.5 \mathrm{dBm}$ for $14.4 \mathrm{ps}$ width pulses, is comparable to that obtained with a classical RZ $33 \%$ optical source. Moreover we established that this module was tunable through a passive optical filtering over $10 \mathrm{~nm}$ without any consistent impact on the receiver sensitivity (less than $1 \mathrm{~dB}$ ). Furthermore, we showed the low chirp of this simple transmitter through chromatic dispersion tolerance investigation demonstrating the high potential of this module for transmission applications. 
Acknowledgments: This work is partly supported by the French ANR projects TONICS and PERSYST II.

\section{References}

[1] Arahira, S., Ogawa, Y., '160-gb/s OTDM signal source with 3R function utilizing ultrafast mode-locked laser diodes and modified NOLM', Photon. Technol. Lett., 2005, 17, pp. 992-994.

[2] Renaudier, J., Lavigne, B., Jourdran, M., Gallion, P., Lelarge, F., Dagens, B., Accard, A., Legouezigou, O., Duan, G.-H., 'First demonstration of alloptical clock recovery at $40 \mathrm{GHz}$ with standard-compliant jitter characteristics based on a quantum-dots self-pulsating semiconductor laser', PDP Th 4.3.4.,Proceedings of ECOC 2005, Vol. 6, Cannes, France, pp. 3132.

[3] Roncin, V., O'Hare, A., Lobo, S., Jacquette, E., Bramerie, L., Rochard, P., Le, Q., Gay, M., Simon, J., Shen, A., Renaudier, J., Lelarge, F., Duan, G., 'Multi-Data-Rate System Performance of a $40 \mathrm{GHz}$ All-Optical Clock Recovery Based on a Quantum-Dot Fabry-Perot Laser', Photon. Technol. Lett., 2007, 19, pp. 1409-1411.

[4] Nishikawa, S., Gotoda, M., Nishimura, T., Tokuda, Y., 'Optical highfrequency pulse generation with wavelength tunability by using a DBR laser with vernier-type gratings', Photon. Technol. Lett., 2005, 17, pp. 1608-1610.

[5] Chung, H. S., Inohara, R., Nishimura, K., Usami, M., 'All-optical multiwavelength conversion of $10 \mathrm{Gbit/s} N R Z / R Z$ signals based on SOA-MZI for WDM multicasting', Electron. Lett., 2005, 41, (7), pp. 432-433.

[6] Shen, A., Provost, J-G., Blache, F., Gariah, H., Mallécot, F., Le Gouezigou, O., Accard, A., Poingt, F., Le Gouezigou, L., Pommereau, F., Rousseau, B., Lalarge, F., Duan, G-H., 'Nearly Fourier-transform limited tunnel injection quantum dash mode-locked Fabry-Perot laser module for tunable pulse generation'. ECOC 2007, Berlin, Germany, PD2.6.

[7] Dorrer, C., 'Investigation of the spectrogram technique for the characterization of picosecond optical pulses'. OFC 2005, Anaheim, CA, USA, OtuB3.

[8] Agrawal, G. P., 'Nonlinear Fiber Optics' (Second Edition, Optics and Photonics, Academic Press), pp 67-69. 
[9] Idler, W., Klekamp, A., Dischler, R., Lazaro, J., Konczykowska, A., 'System performance and tolerances of $43 \mathrm{Gbit} / \mathrm{s}$ ASK and DPSK modulation formats'. ECOC 2003, Rimini, Italy, Th2.6.3.

Authors' affiliations:

G. Girault, M. Gay, S. Lobo, L. Bramerie, M. Joindot, J.C. Simon (CNRS UMR 6082 Foton, PERSYST Platform, ENSSAT / Université de Rennes1, 6 rue Kerampont, 22300 Lannion, France).

Email:persyst@enssat.fr

A. Shen, F. Blache, H. Gariah, F. Mallécot, O. Le Gouezigou, F. Poingt, L. Le Gouezigou, F. Pommereau, B. Rousseau, F. Lelarge, G-H. Duan (AlcatelThales III-V lab, RD 128, 91767 Palaiseau, France).

Figure captions:

Fig. 1 Optical spectral and temporal characterisations.

Fig. 2 Experimental setup.

Fig. 3 Receiver sensitivity at a BER of $10^{-9}$ versus the wavelength. Inset: Eye diagrams corresponding to each curve.

Fig. 4 Penalty at a BER of $10^{-9}$ versus the chromatic dispersion. 
Figure 1
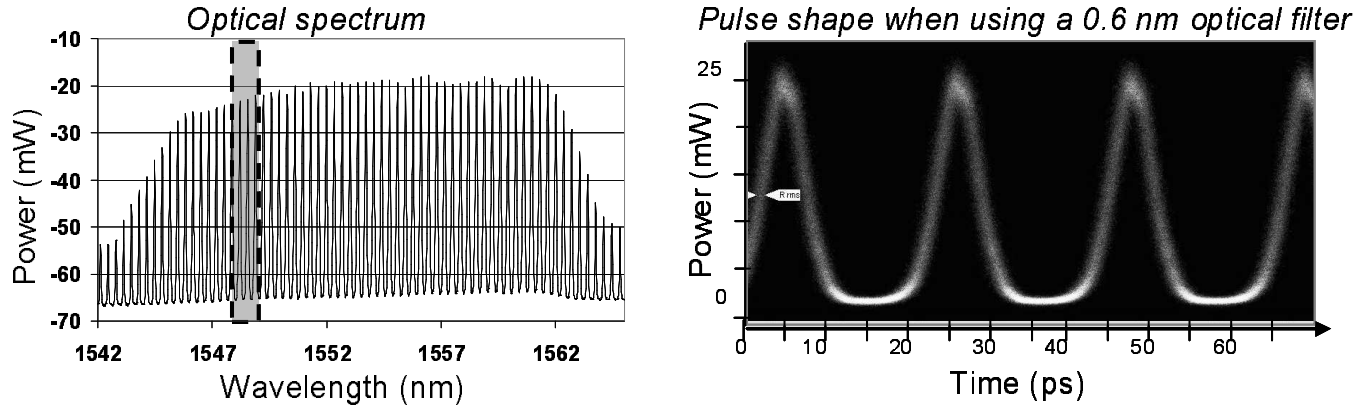
Figure 2

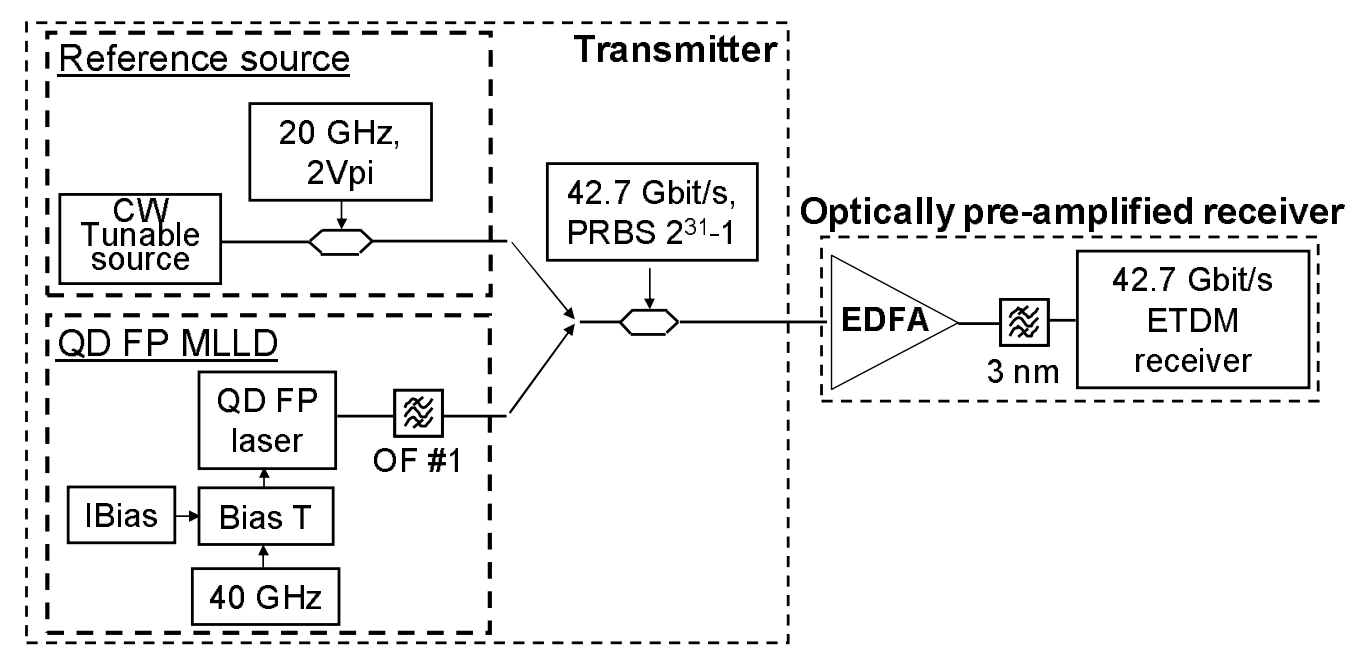


Figure 3

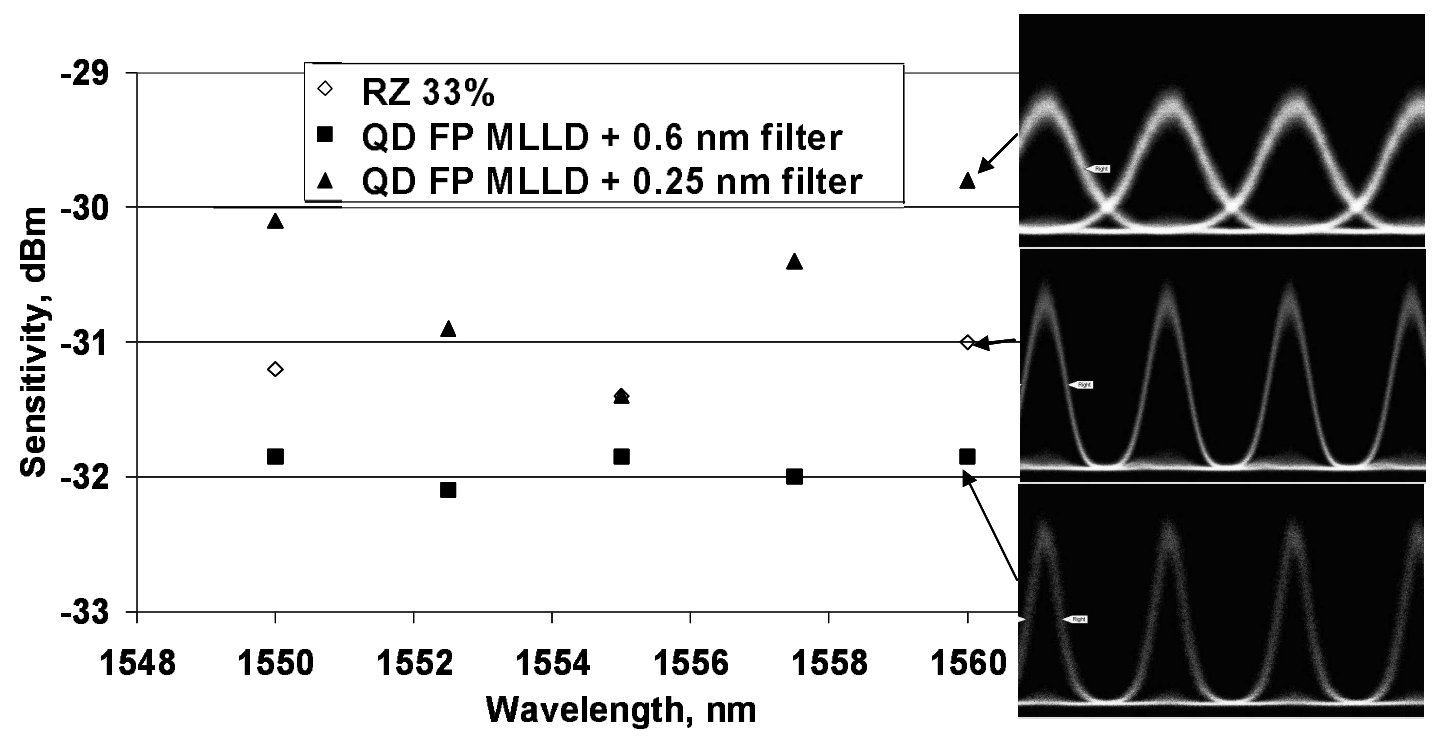


Figure 4

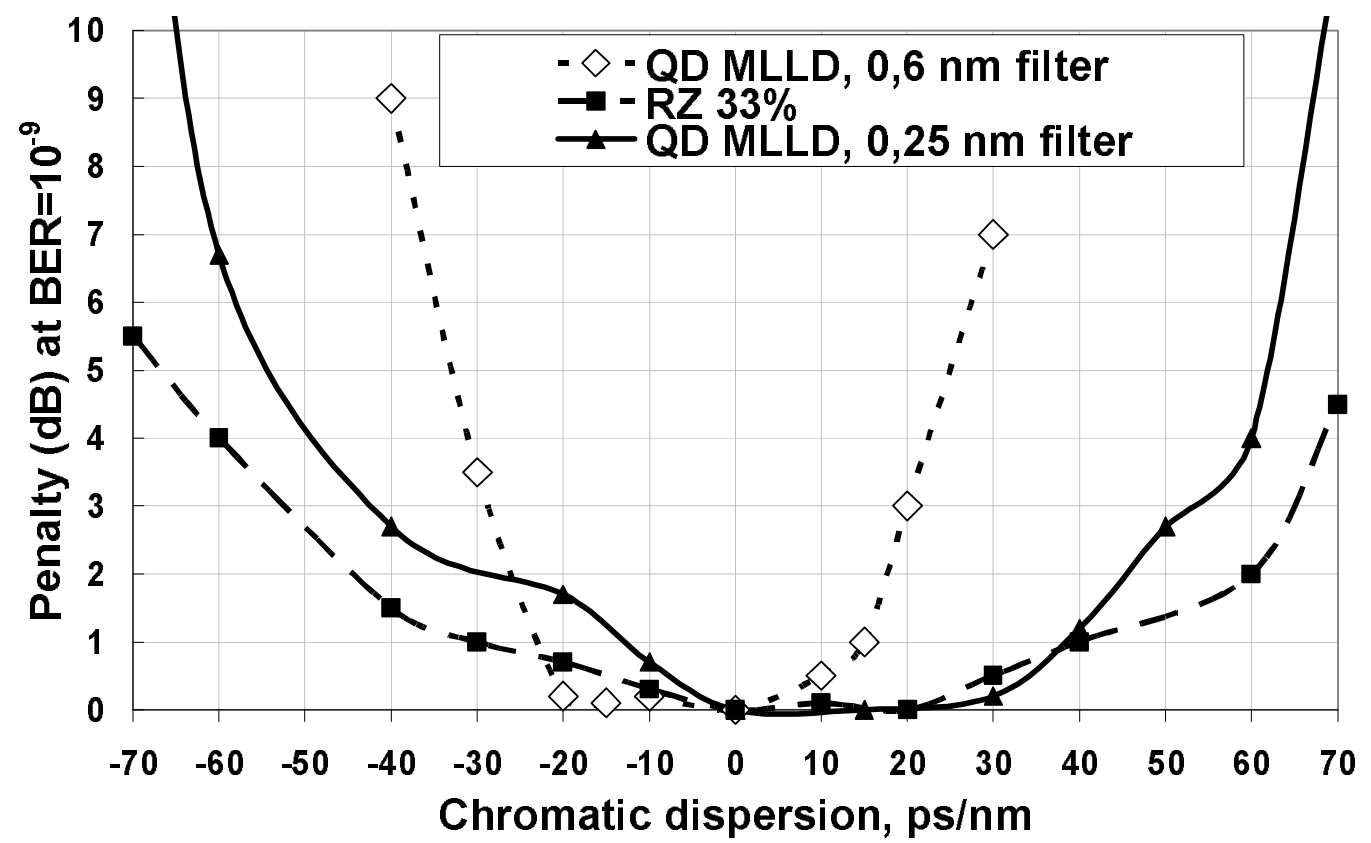

